\title{
A NEW INSTRUMENT FOR OBTAINING INDICATOR DILUTION CURVES USING A RADIOACTIVE TRACER, ${ }^{125}$
}

\author{
BY \\ J. T. HOBBS* AND A. M. FILIPOV† \\ From Peter Bent Brigham Hospital, Boston, Mass., U.S.A., and \\ St. Mary's Hospital, London W.2 \\ Received April 1, 1963
}

The use of indicator dilution curves has now become established as a routine procedure in studies of the circulation. Dyes are the commonly used indicators and the time concentration curve is obtained by intermittent sampling or by a continuous technique with an indwelling needle at a suitable sampling site. More recently radio-iodinated human serum albumin ([125HSA) has been successfully used as the indicator in determining cardiac output. Because of the slow response of earlier nuclear instruments, counting of individual blood samples, each collected over a one-minute period, was the method of choice. The technique was described by Fields (Fields and Seed, 1961). Rapid advances in the design of nuclear equipment have made available detectors of high sensitivity and ratemeters of such rapid response and precision that accurate continuous recording is possible. An apparatus employing this method was described for measuring blood flow in the femoral artery (Hobbs and Edwards, 1962). By simply reversing the technique, i.e. injecting the indicator into the femoral vein and sampling from the femoral artery, apparently reliable cardiac output indicator dilution curves were obtained.

Although this method gave seemingly reliable results the apparatus was bulky and had several disadvantages. The injection was made by hand so that the volume and duration of injection were not exactly reproducible; the continuous curve obtained was linear and needed to be replotted on semilogarithmic graph paper so that the downslope could be extrapolated to zero; the use of $I^{131}$ resulted in the patient receiving a significant radiation dose and required a detector weighing $475 \mathrm{lb}$. $(216 \mathrm{~kg}$.); and the ratemeter and withdrawal pump employed were standard models having many surplus components. A new instrument was, therefore, designed especially for the purpose of obtaining indicator dilution curves by this technique.

The purpose of this paper is to describe the instrument and its laboratory evaluation. The use of I25 labelled albumin ('albumotope', Squibb) introduced many real advantages. (a) A lower net radiation dosage to the patient as well as to the operator (e.g. chest radiograph represents 500-2000 mrad., $50 \mu \mathrm{c} \mathrm{I}{ }^{131}$ albumin i/v represents approximately $500 \mathrm{mrad}$., whereas $50 \mu \mathrm{c} \mathrm{I}{ }^{125}$ albumin i/v results in a dose of $33 \mathrm{mrad}$.). This is despite the isotope's longer half-life ( $\mathrm{t} \frac{1}{2}=60$ days), and is due to the emission of only 'soft' photons of 27.3 and 35.4 Kev. energies and the complete absence of beta radiation (Myers and Vanderleeden, 1960). (b) A much longer refrigerator shelf-life. (c) $Z$ thin crystal can be used because its efficiency at higher energies is very poor, so that very little shielding is needed to reduce background interference. A spectrometer is not required. The small crystal is inexpensive and because little lead is required the unit weighs only $6 \mathrm{lb} .(2.7 \mathrm{~kg}$.).

* Present address: Surgical Unit, St. Mary's Hospital, London W.2. Formerly Assistant in Surgery, Peter Bent Brigham Hospital, and Research Fellow in Surgery, Harvard Medical School, Boston, Mass., U.S.A.

+ Senior Engineer, Tracerlab Division of L.F.E., Waltham 54, Mass., U.S.A. 
An injector unit has been built into the instrument so that either 1 or $2 \mathrm{ml}$. volumes can be delivered in less than $0.25 \mathrm{sec}$. and at the same moment the time axis of the recorder is automatically started ensuring accurate circulation times.

By adding a logarithmic circuit to the ratemeter the curve obtained is logarithmic and can be extrapolated directly. This required the addition of a 'zero suppression' circuit to subtract out any radioactivity already present in the blood at the time of injection. The background subtracted, if recorded 10 minutes after the previous injection, represents the total blood volume (T.B.V.) using the standard dilution equation. A meter is included in the circuit and reads linear at all times so that a rapid visual check is available. A simple switch allows the curve recorded to be linear so that the dispersion of the indicator particles can be both qualitatively and quantitatively studied.

\section{THE INSTRUMENT}

The instrument* is contained in the cabinet of a standard ratemeter (Tracerlab model SC-79), and a TY recorder (Houston Instruments model HR-80) was partly disassembled and inserted into the top of the cabinet. The withdrawal pump and injector unit have been attached to the sides and are easily accessible. The unit is compact (Fig. 1A) and its total weight is $68 \mathrm{lb}$. (31 kg.). The recorder circuit is fully transistorized and includes a scale selector switch with calibration and high voltage channels: background subtraction has two controls, a coarse adjustment with three positions, and a fine control. The mains frequency is used for calibration of the recorder and is 3000 in the U.K. and 3600 in the U.S.A. The amplifier of the recorder at present includes vacuum tubes but it is intended to replace this by a transistorized circuit. The internal arrangement is shown in Fig. 1B.

The withdrawal pump uses a $30 \mathrm{ml}$. syringe and the rate is $10 \mathrm{ml} . / \mathrm{min}$. which has been found to be adequate, but the gear wheels can be easily changed. The helix is a single coil of polyethylene tubing (size No. 3 English) and the internal volume of this helix in the well is approximately $1 \mathrm{ml}$. By means of a three-way stopcock, washout fluid can be withdrawn from a suitable container and this prevents clotting of blood and serious contamination in the helix. The washout solution contains $\mathbf{5 0}$ units heparin per ml., and by using this immediately the curve is recorded the background of the helix remains at 300-400 counts per minute (c.p.m.).

The injector unit has a solenoid which rapidly advances the plunger of the $10 \mathrm{ml}$. syringe. A ratchet is built into the advancement mechanism and a lever cocks the injector for a 1 or $2 \mathrm{ml}$. volume injection. After the last injection $0.3 \mathrm{ml}$. remains in the syringe so that the fully-loaded syringe contains $9.3 \mathrm{ml}$. of solution. The injection solution contains $25-30 \mu \mathrm{c} \mathrm{I} \mathrm{I}^{125}$ activity per $\mathrm{ml}$. For dog studies 5-10 $\mu \mathrm{c}$ per ml. is adequate.

The recorder includes a null-seeking servo which moves an ink pen in proportion to the input signal from the ratemeter on the vertical or ' $Y$ ' axis, and a plug-in synchronous timing motor to move the pen on the horizontal or ' $T$ ' axis. A gear ratio was used which produced a writing speed of 3 in. a minute so that $1 / 10$ th in. represents 2 seconds. The controls are a wide range zero adjustment and a continuously variable attenuator. Standard $8 \frac{1}{2}$ in. $\times 11$ in. $(21.5 \mathrm{~cm} . \times 28 \mathrm{~cm}$.) sheet graph paper is used, and for the logarithmic recordings a special paper has been designed, though standard 3-cycle semilogarithmic paper may be used. The logarithmic scale is fixed at 3 cycles, 100 to 100,000 c.p.m. The accuracy of the recorder unit is 0.5 per cent static or constant velocity below 7 in. $(17 \cdot 7 \mathrm{~cm}$.) $/ \mathrm{sec}$.

The mechanical-electrical layout is shown in Fig. 2. Two 18-gauge needles are placed in the patient's artery and vein at suitable sites and are connected to the machine by sterile disposable plastic extension sets (William Warne W142 or Baxter R33). When the withdrawal pump is started blood is drawn through the helix in the well at a constant rate of $10 \mathrm{ml}$. per minute. The activity is monitored by the ratemeter and a logarithmic or linear signal is selected and transmitted to the recorder. After the withdrawal pump has been switched on the injector may be discharged. At the moment the injector is 'fired' the time axis of the recorder is set in motion. This enables accurate appearance, peak, and recirculation times, as well as calculation of the mean transit time in the primary circulation. As soon as recirculation appears the three-way stopcock is turned so that washout solution is drawn through the helix.

* This instrument, the 'Rheometer', was assembled by W. P. Churchill, Tracerlab Inc., U.S.A.: a later improved model is the 'Hematron', manufactured by Tracerlab Division of L.F.E., U.S.A. 


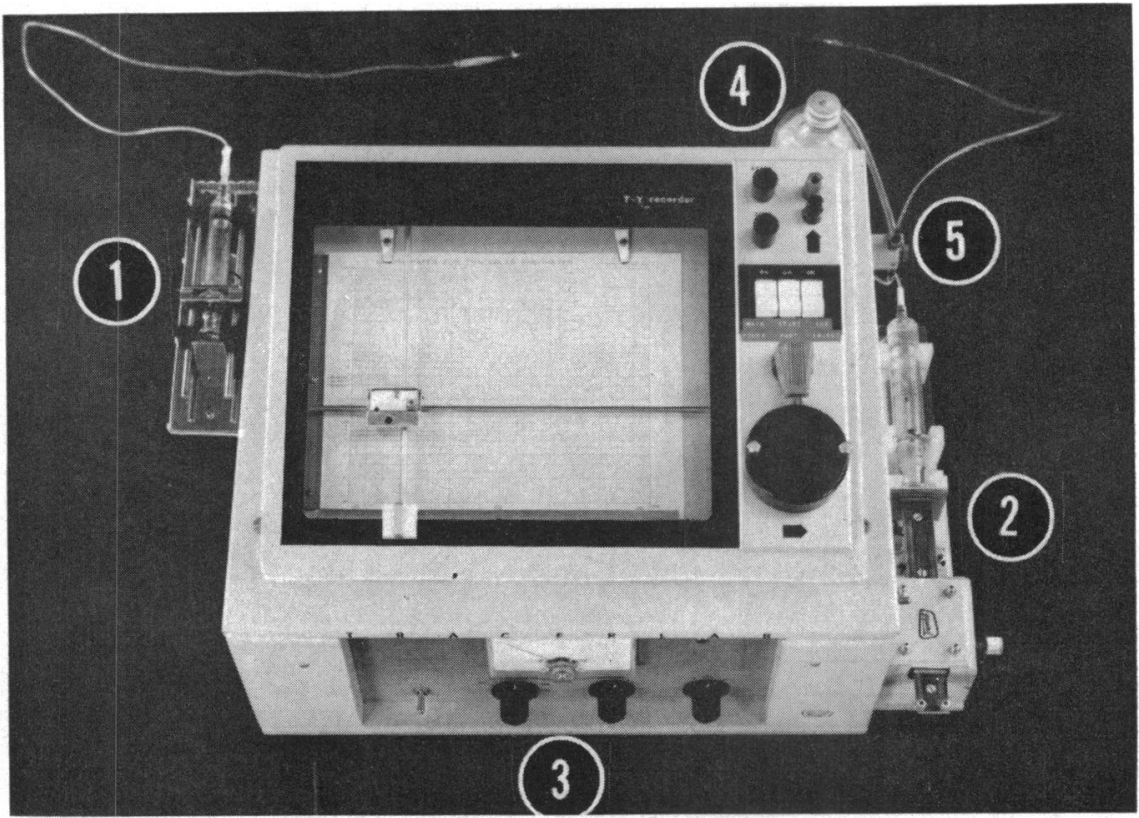

A

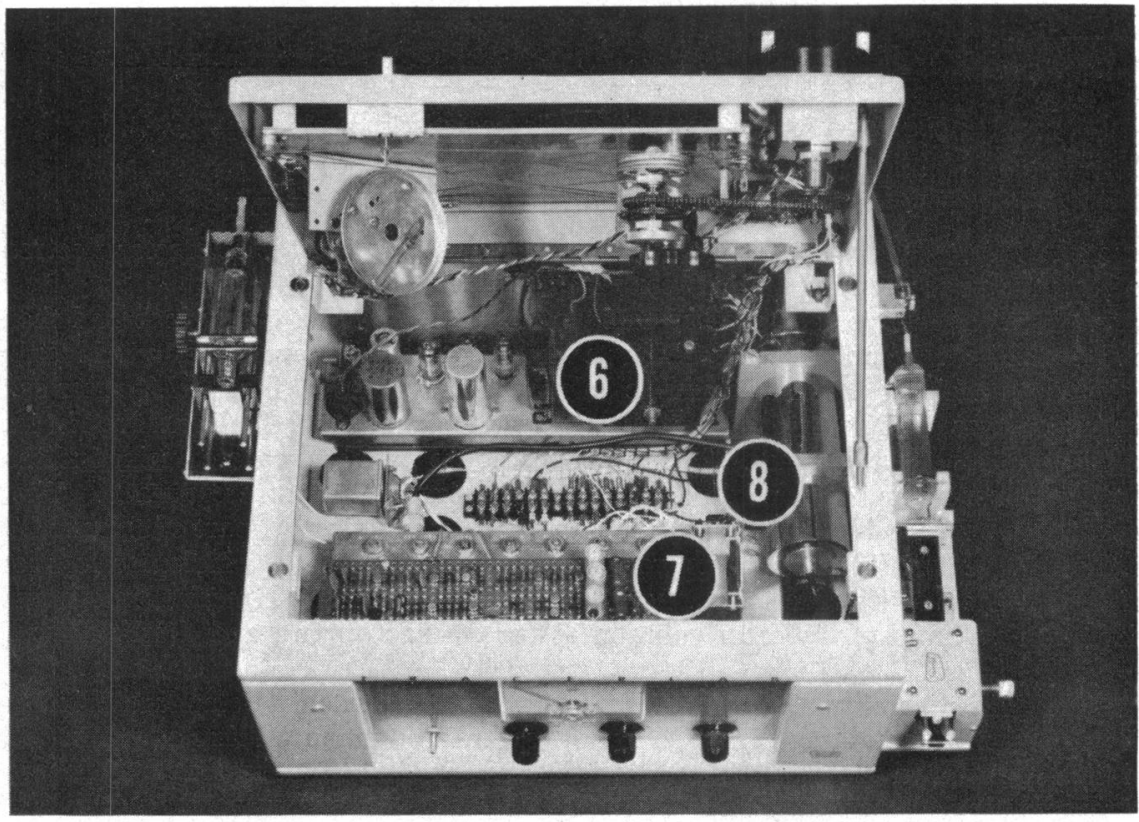

B

FIG. 1.-(A) the instrument; (B) the internal layout. 1, injector unit; 2, withdrawal pump; 3 , linear meter and controls; 4 , washout bottle; 5 , three-way stopcock; 6 , recorder amplifier; 7, ratemeter electronics; and 8, detector unit. 


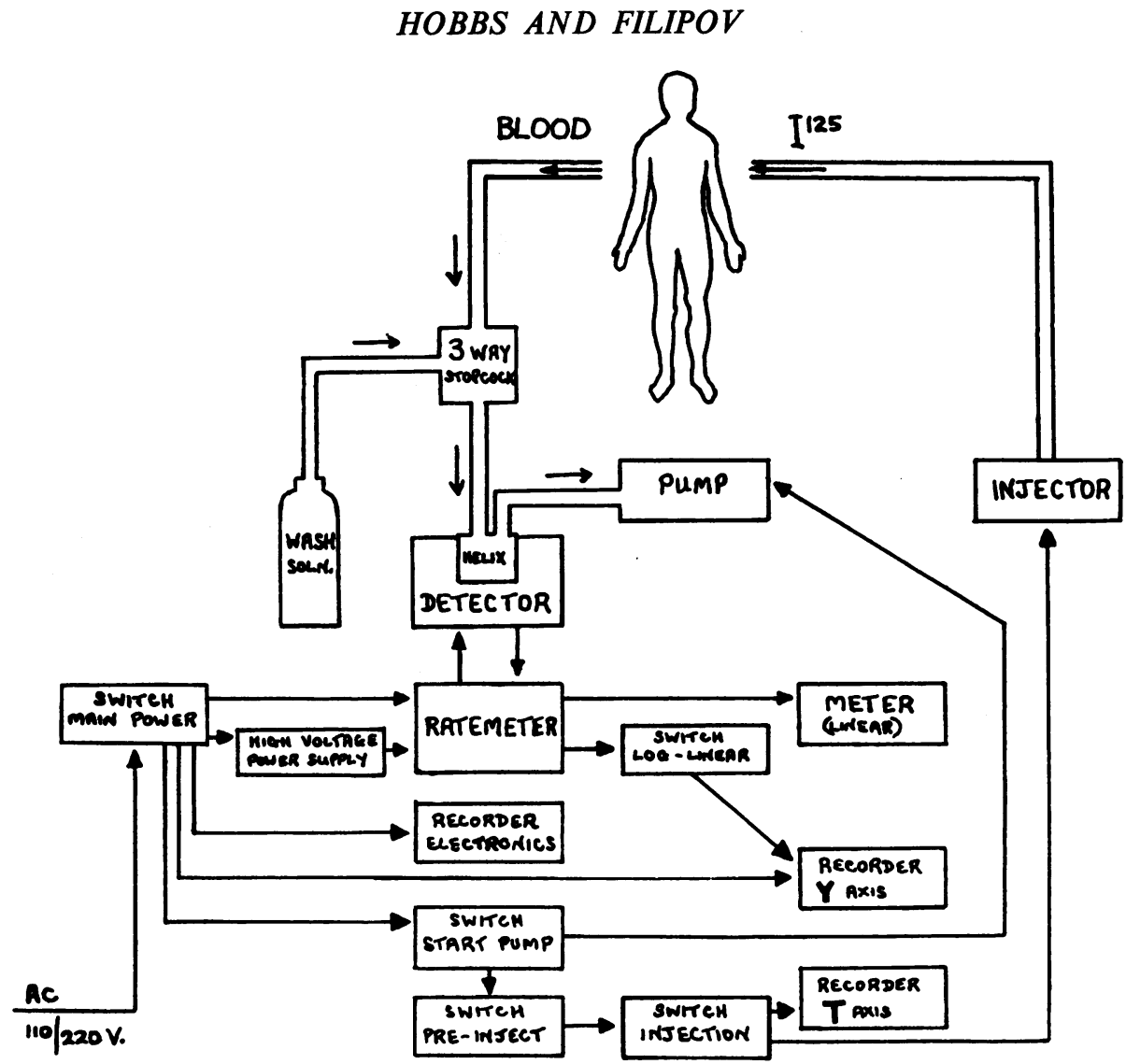

Fig. 2.-Block diagram of the mechanical-electrical layout.

\section{LABORATORY EVALUATION OF THE INSTRUMENT}

The Ratemeter. A precision pulse-generating circuit was used to test the ratemeter electronics and the unit was found to have an accuracy of within 3 per cent of full scale.

The Injector. The accuracy of the injector unit was tested by loading the syringe and then repeatedly injecting $1 \mathrm{ml}$. into a $25 \mathrm{ml}$. volumetric flask, having a very long neck to prevent accidental loss by splashing, which was weighed on a high precision automatic balance (Stanton model No. EM.2) after each injection. The first series of tests was done using water and the syringe was loaded to $9.3 \mathrm{ml}$. and fired in $1 \mathrm{ml}$. volumes until empty. This was repeated six times. The whole procedure was then repeated using indicator solution, i.e. $30 \mu \mathrm{c} \mathrm{I} \mathrm{I}^{125}$ albumin per $\mathrm{ml}$. in isotonic saline, and four sets of measurements were made. The syringe was then siliconized before each loading, by application of a solution containing 1 part of silicone MS 550 and 2 parts of diethyl ether. Sets of measurements were made with water and then indicator solution as before. The results of each of these series of tests are given in Table I. A final set of measurements was then made using $2 \mathrm{ml}$. injection volumes of indicator solution as for cardiac output, and these values are given in Table II.

The Instrument. The reliability of the injector unit having been tested, 41 standard solutions were now prepared by injecting $1 \mathrm{ml}$. (containing $12 \mu \mathrm{c}$ ) $\mathrm{I}^{125}$ human serum albumin into 1 litre of water. After shaking well, each solution was drawn through the detector and the resultant count recorded on linear graph paper with full scale representing 4500 c.p.m. The results of these repeated standards are given in Table III. Expressing the standard deviation as a percentage of the mean represents the overall instrument precision.

The Standard. Standard solutions were prepared by injecting $1 \mathrm{ml}$. volumes of the same indicator solution, containing $25 \mu \mathrm{c} \mathrm{I} \mathbf{I}^{125}$ albumin, into 1 litre of water and into 1 litre of blood (expired blood obtained from the Transfusion Service). These solutions were drawn through the instrument and the activity recorded. 
TABLE I

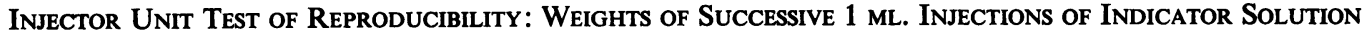

\begin{tabular}{|c|c|c|c|c|c|c|c|c|c|}
\hline & \multicolumn{9}{|c|}{ Position of syringe (ml.) } \\
\hline & $9-8$ & $8-7$ & $7-6$ & $6-5$ & $5-4$ & $4-3$ & $3-2$ & $2-1$ & $1-0$ \\
\hline \begin{tabular}{lllll}
\multicolumn{3}{l}{ Water: } \\
tions (gean weight of & six injec- \\
S.D. & $\ldots$ & $\ldots$ & $\ldots$ & $\ldots$ \\
\end{tabular} & $\begin{array}{c}0.9458 \\
+0.018\end{array}$ & $\begin{array}{r}0.9861 \\
\pm 0.021 \\
\end{array}$ & $\begin{array}{c}0.9981 \\
\pm 0.031 \\
\end{array}$ & $\begin{array}{r}0.9990 \\
\pm 0.015\end{array}$ & $\begin{array}{r}0.0106 \\
\pm 0.020 \\
\end{array}$ & $\begin{array}{r}1.0102 \\
\pm 0.029 \\
\end{array}$ & $\begin{aligned} & 0.9964 \\
& \pm 0.062 \\
&\end{aligned}$ & $\begin{array}{ll} & 1.0118 \\
\pm & 0.015 \\
\end{array}$ & $\begin{array}{r}1.0115 \\
\pm 0.019 \\
\end{array}$ \\
\hline 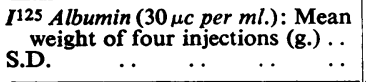 & $\begin{array}{r}0.9036 \\
\pm 0.284 \\
\end{array}$ & $\begin{array}{r}0.9591 \\
\pm 0.039 \\
\end{array}$ & $\begin{array}{r}1.0254 \\
\pm 0.036 \\
\end{array}$ & $\begin{array}{l}0.9948 \\
\pm 0.022 \\
\end{array}$ & $\begin{array}{r}0.9987 \\
\pm 0.029 \\
\end{array}$ & $\begin{array}{r}0.9887 \\
+0.029 \\
\end{array}$ & $\begin{array}{l}0.9853 \\
\pm 0.013 \\
\end{array}$ & $\begin{array}{r}1.0186 \\
\pm 0.029 \\
\end{array}$ & $\begin{array}{r}1.0131 \\
\pm 0.009 \\
\end{array}$ \\
\hline $\begin{array}{l}\text { Water and Siliconized Syringe: } \\
\text { Mean weight of six injections (g.) } \\
\text { S.D. } \quad \text {. } \\
\end{array}$ & $\begin{array}{r}0.9065 \\
\pm 0.066 \\
\end{array}$ & $\begin{array}{r}1.0042 \\
\pm 0.052 \\
\end{array}$ & $\begin{array}{r}1.0102 \\
\pm 0.028 \\
\end{array}$ & $\begin{array}{r}1.0022 \\
\pm 0.018 \\
\end{array}$ & $\begin{aligned} & 1.0141 \\
& \pm 0.042 \\
&\end{aligned}$ & $\begin{array}{r}1.0212 \\
\pm 0.047 \\
\end{array}$ & $\begin{array}{r}1.0080 \\
\pm 0.039 \\
\end{array}$ & $\begin{array}{r}1.0044 \\
\pm 0.029 \\
\end{array}$ & $\begin{array}{r}1.0243 \\
\pm 0.019 \\
\end{array}$ \\
\hline 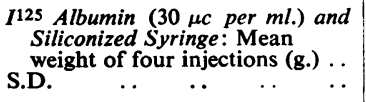 & $\begin{array}{c}0.9799 \\
\pm 0.019\end{array}$ & $\begin{array}{c}1.0184 \\
\pm 0.011\end{array}$ & $\begin{array}{r}1.0169 \\
\pm 0.010\end{array}$ & $\begin{array}{r}1.0246 \\
\pm 0.012\end{array}$ & $\begin{array}{l}1.0233 \\
\pm 0.013\end{array}$ & $\begin{aligned} 1.0269 \\
\pm 0.014\end{aligned}$ & $\begin{array}{l}1.0116 \\
\pm 0.013\end{array}$ & $\begin{array}{l}1.0275 \\
\pm 0.015\end{array}$ & $\begin{array}{r}1.0213 \\
\pm 0.008\end{array}$ \\
\hline
\end{tabular}

TABLE II

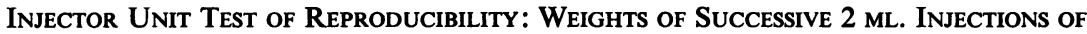
I125 Albumin Solution (30 $\mu \mathrm{c}$ Per mL.) Using Siliconized Syringe

\begin{tabular}{|c|c|c|c|c|c|}
\hline & & \multicolumn{4}{|c|}{ Position of syringe (ml.) } \\
\hline & & $9-7$ & $7-5$ & $5-3$ & $3-1$ \\
\hline $\begin{array}{l}\text { Mean weight of six injections (g.) } \\
\text { S.D. } \quad . . \quad \ldots \quad \ldots\end{array}$ & $\begin{array}{l}\cdots \\
\cdots\end{array}$ & $\begin{array}{l}1.9329 \\
\pm 0.091\end{array}$ & $\begin{array}{l}2.0675 \\
\pm 0.011\end{array}$ & $\begin{array}{l}1.9663 \\
\pm 0.050\end{array}$ & $\begin{aligned} & 2.0103 \\
\pm & 0.099\end{aligned}$ \\
\hline
\end{tabular}

TABLE III

Activity (COUNTS Per minute) Recorded from 41 Similar Standard Solutions, each MADE BY INJECTING 1 ML. I125 SeRUM AlbUMin (CONTAINING $12 \mu \mathrm{c}$ ) INTO 1 Litre OF WATER

\begin{tabular}{|c|c|c|c|c|}
\hline & \multicolumn{4}{|c|}{ Position of syringe (ml.) } \\
\hline & $4-3$ & $3-2$ & $2-1$ & $1-0$ \\
\hline $\begin{array}{l}\text { Mean activity of } 10 \text { standard solutions .. } \\
\text { S.D. } \quad . \quad \ldots \quad \ldots \quad \ldots \quad \ldots\end{array}$ & $\begin{array}{c}3781 \\
\pm 161 \cdot 3\end{array}$ & $\begin{array}{c}3804 \\
\pm 222 \cdot 6\end{array}$ & $\begin{array}{c}3865 \\
\pm 166 \cdot 7\end{array}$ & $\begin{array}{c}3786 \\
\pm 152 \cdot 4\end{array}$ \\
\hline
\end{tabular}

\section{RESULTS}

The values obtained in the injector unit tests of reproducibility are given in Tables I and II. The mean and standard deviation of each group of $1 \mathrm{ml}$. injectate volumes are graphically presented in Fig. 3. It is seen in all groups that the initial injection $(9-8 \mathrm{ml}$.), made when the plunger was farthest out of the syringe barrel, always gave a low volume as measured by weight. This was most marked in the group using albumin solution in a plain syringe (mean $0.9036 \mathrm{~g}$.); in this same group the next injection $(8-7 \mathrm{ml}$.) was also low (mean $0.9591 \mathrm{~g}$.) but was then followed by a high compensatory value (mean $1.0254 \mathrm{~g}$. at 7-6 ml.). The greatest irregularities were seen when albumin solution was injected from a plain syringe.

When the syringe was siliconized, the second injection $(8-7 \mathrm{ml}$.) was just above $1 \mathrm{~g}$. and the subsequent injections tended to be high so that at the end of the run the residual volume was less 


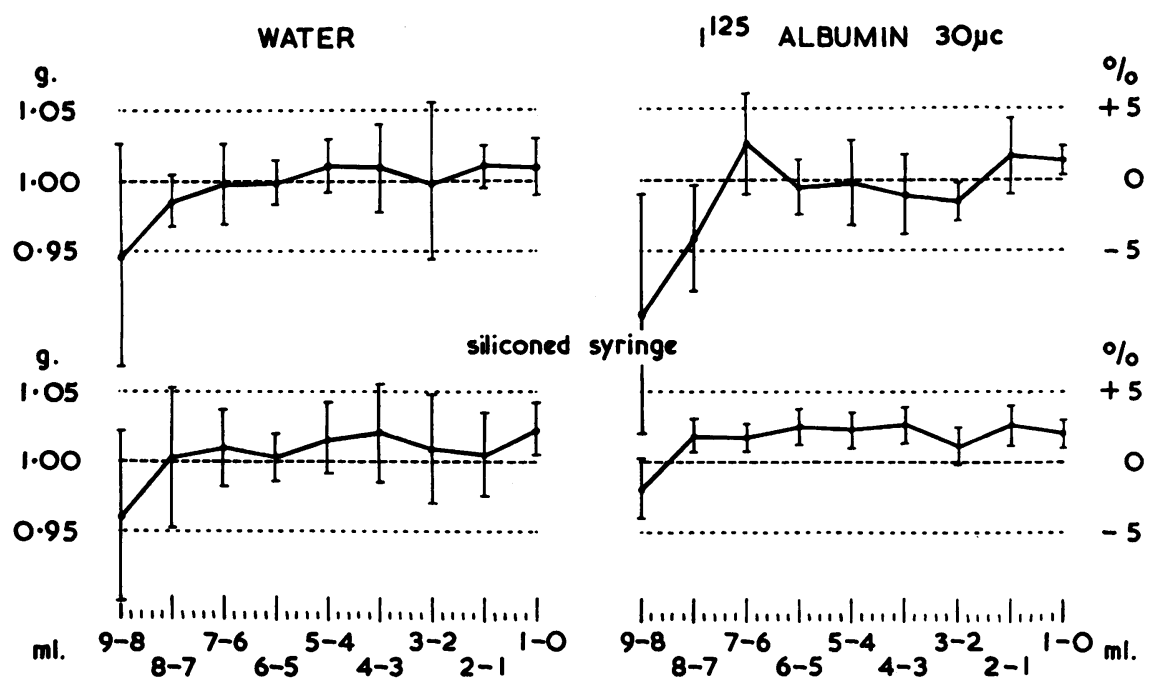

FIG. 3.-Variability of the injector unit. Mean and standard deviation of the weights of successively injected $1 \mathrm{ml}$. volumes of water and of albumin solution.

than the expected $0.3 \mathrm{ml}$. Whereas albumin had given an irregular curve when injected from a plain syringe, the results were satisfactory with a standard deviation of less than 3 per cent, apart from the 4 per cent for the first position $(9-8 \mathrm{ml}$.), when a siliconized syringe was used.

When the volume of solution injected was $2 \mathrm{ml}$., as used in the determination of cardiac output, the results showed wider variation but the standard deviation was never more than 5 per cent of the mean for each position. Weighing $2 \mathrm{ml}$. volumes was only done for albumin solution used in a siliconized syringe and the results are given in Table II.

To test the overall reproducibility of the instrument a series of standard solutions was made and each was then drawn through the helix. In order to obtain a large number of standards the activity of the injectate was reduced from 30 to $12 \mu \mathrm{c}$ per $\mathrm{ml}$. The recorder attenuation and scale setting was adjusted so that 4500 c.p.m. represented the full scale $(7 \mathrm{in} .(17 \cdot 7 \mathrm{~cm}$.)), thus increasing the accuracy of the readings. The results of this series of tests are given in Table III. The mean of the 41 standards was 3808 c.p.m. (S.D. \pm 171 ). The variability of the instrument may be stated by expressing the standard deviation as a percentage of the mean, and the overall instrument precision was therefore 4.5 per cent in the series of 41 standards.

When the standard solutions were made by injecting $1 \mathrm{ml}$. of the same solution into 1 litre of either water or blood, similar results were obtained. Thus if the standard is prepared in water an error is not introduced.

\section{APPLiCATION IN THE DOG}

Two dogs were anæsthetized with intravenous 'nembutal' $(30 \mathrm{mg}$. per $\mathrm{kg}$.) and the femoral vessels of one leg exposed through a small incision. Vinyl Rochester needles, size 18 gauge, were placed in the artery and in the vein, just distal to the inguinal ligament. The instrument was connected to these needles and $1 \mathrm{ml}$. of $\mathrm{I}^{125}$ serum albumin, containing $10 \mu \mathrm{c}$, was injected into the femoral artery and a linear time-concentration curve recorded from the activity of the blood withdrawn from the femoral vein. Typical curves obtained are reproduced in Fig. 4. The femoral artery flow was $71 \mathrm{ml}$. per minute in the $16 \mathrm{~kg}$. dog, and $154 \mathrm{ml}$. per minute in the $33 \mathrm{~kg}$. dog. When $2 \mathrm{ml}$. $(20 \mu \mathrm{c})$ were injected into the femoral vein, satisfactory cardiac output curves were obtained from the femoral artery blood. 


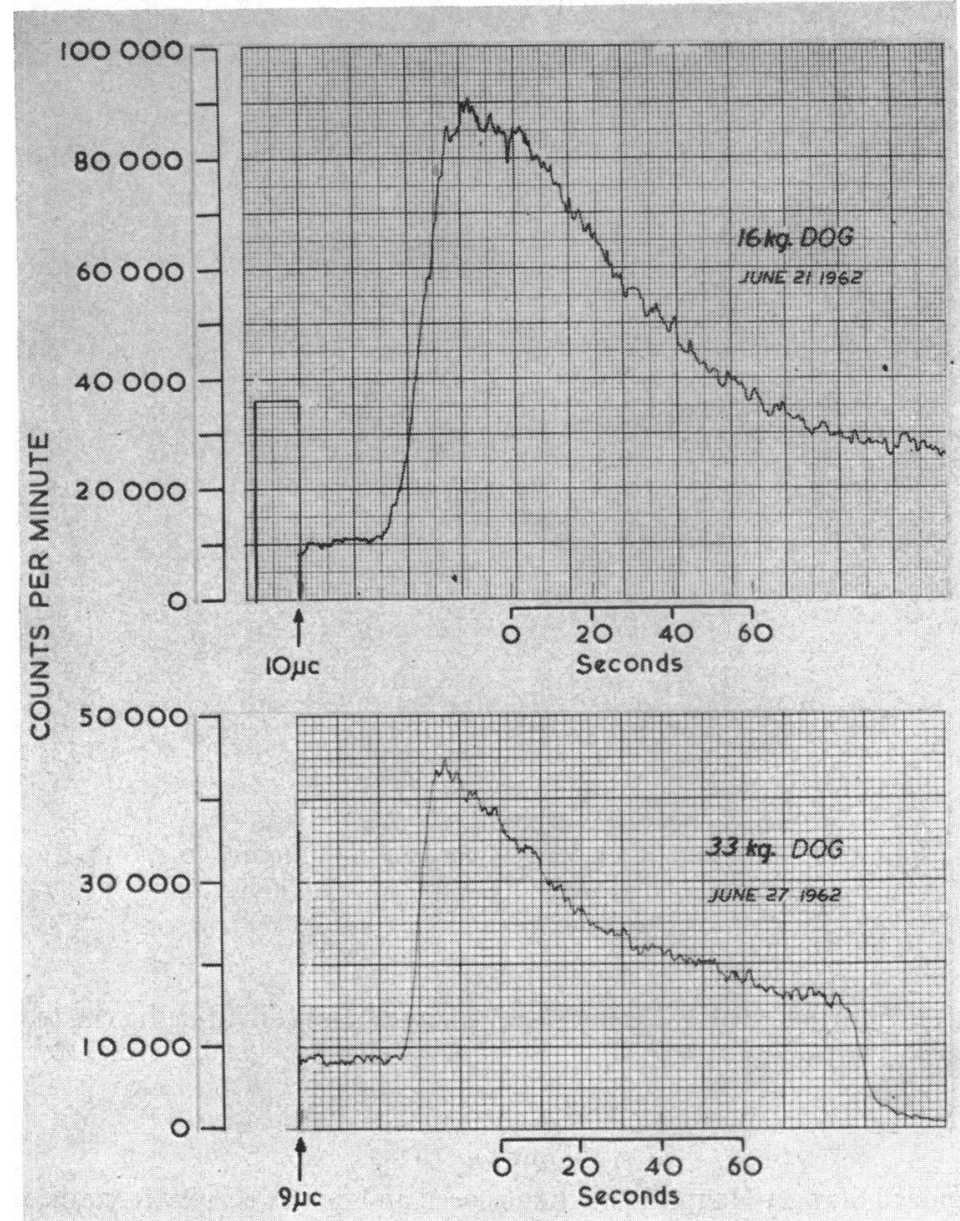

FIG. 4.-Typical dilution curves after injection of radio-iodinated serum albumin into femoral artery of a $16 \mathrm{~kg}$. and of a $33 \mathrm{~kg}$. dog. The quantitative results were $71 \mathrm{ml}$. and $154 \mathrm{ml}$. per minute respectively.

\section{Application in Man}

The method has been used in man employing the technique previously described (Hobbs and Edwards, 1962). An 18-gauge Cournand needle was introduced pointing upstream in the femoral artery just distal to the inguinal ligament and an 18-gauge spinal needle was placed in the femoral vein alongside. Cardiac output was obtained by injecting $2 \mathrm{ml}$. (50-60 $\mu \mathrm{c}) \mathrm{I}^{125}$ radio-iodinated serum albumin into the femoral vein and sampling from the femoral artery; a typical logarithmic time concentration curve is shown in Fig. $5.1 \mathrm{ml}$. $(30 \mu \mathrm{c})$ will produce satisfactory cardiac output curves in man but since the irradiation danger is negligible the larger dose is preferred because a steeper curve is produced.

Time concentration curves for femoral artery flow are obtained by injecting $1 \mathrm{ml}$. (25-30 $\mu \mathrm{c})$ $\mathrm{I}^{125}$ serum albumin into the femoral artery and recording the activity in a continuous blood sample withdrawn from the femoral vein. A logarithmic scale enables direct extrapolation for determination of flow, and a linear recording shows the indicator dispersion more clearly. Flow after reactive 


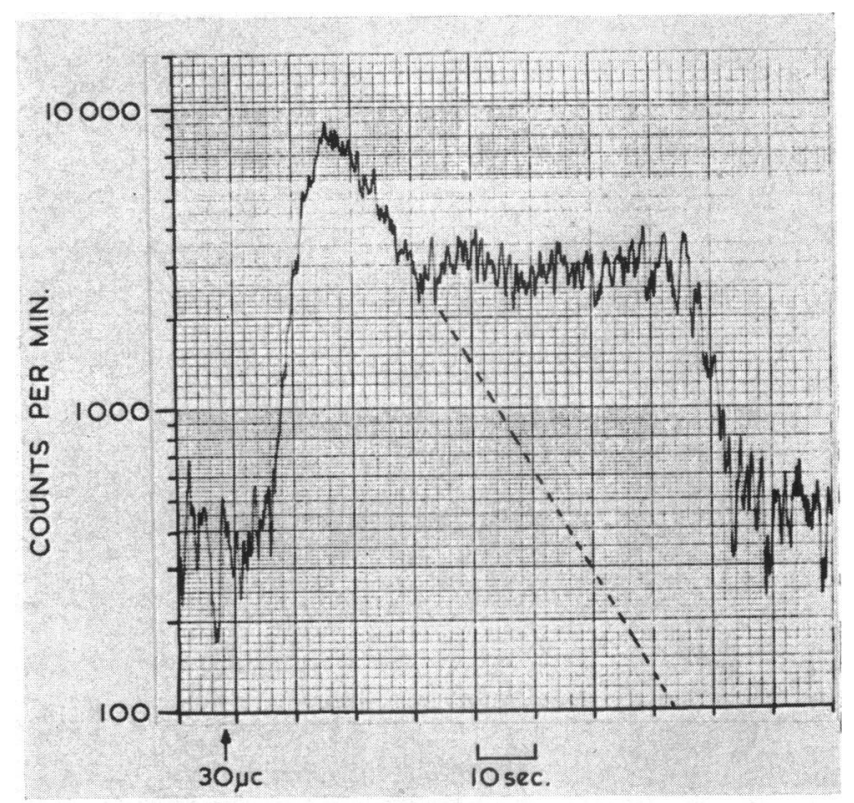

FIG. 5.-Logarithmic record of cardiac output curve in a $74 \mathbf{~ k g}$. man. The flow was $6 \cdot 1$ litres per minute.

hyperæmia and after pharmacological vasodilatation can be obtained using the techniques previously described (Hobbs and Edwards, 1962).

\section{Calculations}

Flow. The standard Stewart-Hamilton method is used and flow is derived from the formula,

$$
F=\frac{I}{s C \times t} \mathrm{ml} . / \mathrm{min} \text {., }
$$

where $F=$ blood flow in $\mathrm{ml} . / \mathrm{min}$., $I=$ activity of standard $\times$ volume of injectate $\times 1000$ (the dilution), $s C=$ sum of the concentrations of the primary curve, and $t=$ the time interval between these concentrations in minutes.

Total Blood Volume. This is derived from the standard dilution equation,

$$
\text { T.B.V. }=\frac{I}{B_{2}-B_{1}} \mathrm{ml} \text {., }
$$

where $I=$ the activity of standard $\times$ volume of injectate $\times 1000, B_{1}=$ blood background before injection, and $B_{2}=$ blood background 10 minutes after the injection.

Mean Transit Time. The formula used is,

$$
\text { M.T.T. }=\text { appearance time }+\frac{s C t \times t}{s C} \text { sec., }
$$

where $s C=$ sum of the concentrations at suitable time intervals $\left(C_{1}+C_{2}+C_{3}+\right.$ etc. $), s C t=$ sum of each of these connexions $\times$ sample number $\left(C_{1} \times 1+C_{2} \times 2+C_{3} \times 3+\right.$ etc. $)$, and $t=$ time interval in seconds.

Limb Blood Volume. The effective vascular space between the injection and sampling sites is deduced from the fact that

$$
\text { L.B.V.=M.T.T. } \times \text { B.F. ml. }
$$

where M.T.T. $=$ mean transit time in seconds, and B.F. $=$ limb blood flow as ml. per second. 


\section{SUMMARY}

A compact instrument for obtaining indicator-dilution curves using a radioactive indicator has been described. This instrument is designed for use with I $^{125}$-labelled human serum albumin. The advantages of $I^{125}$ over the previously used $I^{131}$ include (a) both the patient and the operator receive a much smaller radiation dose; (b) a smaller, lighter, and cheaper detector unit can be employed; and (c) the storage life is much longer. Because the label is already attached to albumin there is no escape of indicator from the vascular space during the primary circulation.

An automatic injector is included in the instrument. The activity may be recorded logarithmically for direct extrapolation. The permanent record is made on standard $8 \mathrm{in} . \times 11 \mathrm{in} .(21 \cdot 5 \times$ $28 \mathrm{~cm}$.) file paper. The instrument is explosion proof and may be used in the operating room. It is compact and portable, weighing $31 \mathrm{~kg}$. Safety override features prevent faulty techniques and the method is easily carried out by one person.

The instrument has been tested in the laboratory and details of the injector unit's performance are given. The overall instrument precision was found to be \pm 4.5 per cent when a solution of static concentration was used. Flow was determined by comparison of a suitable time concentration curve with a standard. This standard could be prepared in water and experiments showed that the same result was obtained for water as for blood. By contrast, use of dye as indicator requires the use of each patient's blood for the standard.

The mathematical formulæ used to obtain the various circulatory indices are given. A nomogram has been constructed in the form of a simple plastic overlay which can be placed on the recorded curves and the various parameters immediately read off (Filipov and Hobbs, 1963). The application of the method to the determination of cardiac output and femoral artery flow in the dog and in man are briefly described. Typical curves are shown. The instrument may be used whenever indicator dulution curves are required. Preliminary work on renal flow is at present being carried out and measurement of carotid blood flow is contemplated.

The authors are indebted to Dr. E. A. Edwards of the Peter Bent Brigham Hospital and Harvard Medical School in whose laboratories the idea was born and developed; to Professor W. T. Irvine of St. Mary's Hospital for his encouragement in the clinical application of this work; and to Professor W. S. Peart for helpful criticism. Our thanks are also due to Tracerlab Inc. for their unfailing support and to Dr. G. Lindenblatt of E. R. Squibb and Sons, New Jersey, who supplied the I125-labelled albumin. One of the authors (J.T.H.) was the recipient of a Wellcome Research Travel Grant.

\section{REFERENCES}

Fields, T., and Seed, L. (1961). Clinical Use of Radioisotopes, 2nd ed., p. 118. Year Book Publishers, Chicago.

Filipov, A. M., and Hobbs, J. T. (1963). A nomogram for indicator-dilution curves used in the study of the circulation. Awaiting publication.

Hobbs, J. T., and Edwards, E. A. (1962). Measurement of blood-flow in the femoral artery; A simplified apparatus. using the indicator-dilution principle. Lancet, 2, 273.

Myers, W. G., and Vanderleeden, J. C. (1960). Radioiodine-125. J. nucl. Med., 1, 149. 